\title{
Experimental investigations and optimization of process parameters of meshed-wick heat pipe
}

\author{
B.Ch.Nookaraju ${ }^{l}$, B. Hemanth $\mathrm{Sai}^{2}$, K.V.N.S Himakar ${ }^{2}, N$. Limba Reddy ${ }^{2}, N$ Sateesh $^{3}$ \\ ${ }^{1}$ Associate Professor, Mechanical Department, GRIET, Hyderabad, India \\ ${ }^{2} 2$ UG Student GRIET, Mechanical Engineering Department, Hyderabad, India. \\ ${ }^{3}$ Professor, Mechanical Department, GRIET, Hyderabad, India
}

\begin{abstract}
Heat pipes are used to transfer heat, which are hollow cylindrical shape device filled with small amount of working fluid, which can change its phase. The rate of heat transfer in heat pipes compared to normal heat exchanging devices is more. Depending on the applications of heat transfer various heat pipes are being designed. Methanol fluid is used with $50 \%$ fill ratio. It is made of copper with outer diameter of $15.88 \mathrm{~mm}$ and inner diameter of $14.88 \mathrm{~mm}$. It consists of a screen mesh made of copper powder inside it with thickness of $0.5 \mathrm{~mm}$. Due to heat input methanol changes its phase from liquid to vapor. The vapor loses its heat and changes its phase back to liquid in the condenser. At the condenser section the vapour gives up it heat and changes its phase from vapour to liquid. The screen mesh assists the flow of condensed working fluid through capillary action. Optimized the results by "Taguchi method" using "Minitab software". The Thermal analysis was done with the optimum conditions, which were obtained as a result from the optimization method by Ansys Fluent software. Then finally compared the thermal parameters obtained from experiments with the Thermal analysis result. It is found the maximum heat transfer rate is optimized using meshed wick heat pipe conditions.
\end{abstract}

\section{Introduction}

Usage of Two Phase Cooling Technology has remarkably improved the Cooling setups of the electronic devices. Heat pipe has working fluid embedded inside the chamber, which take advantage of capillary pressure to transfer the liquid from condenser section to evaporator section. They have low drop of temperature. Investigations had been done on the effect of pore size on the capillary pressure.

Heat pipes provide the cooling solutions to the advance devices developed like multi core processors. Boiling heat transfer limit is more important than capillary limit to find out the limitations of the chamber. Semenic and catton [13], conducted many experiments by varying thickness of the wick, powder size to evaluate its performance.

Visual observation provides the insight on the boiling in evaporator chamber at different orientations. This paper describes about the performance of heat pipe with sintered powder mesh wick varying the factors and recording the thermal performance parameters and finding the optimum condition of operation. FMHP consisting of composite fibre wick can transfer the heat load of 3 was effectively up to $100 \mathrm{~mm}$ distance with heatpipe thermal resistance ranging $0.25-0.45 \mathrm{oC} / \mathrm{W}$ by handheld device [1]. Dependence of thermal performance on the particle size \& thickness of wick was investigated [2]. The minimum evaporative \& critical

\footnotetext{
* Corresponding author: nookarajubch@yahoo.com
}

heat loads, resistance are nearly unaffected when a smooth copper surface immersed in methanol or acetone would remain wet even after $3 \mathrm{hrs}$ of exposured time [3]. The experimental results confirmed the effectiveness of continuous phase-change heat transfer inside the plastic board [4]. Thermal conductivity of simple powder particle is $31.5 \%$ of sintered layer value. Thermal conductivity of the sintered layer is $4.8 \%$ of its solid materials [5]. Hea ppes can be used as thermal links \& heat exchangers in different system fo efficient energy saving \& environmental protection [6]. The CLHP transported $12.17 \mathrm{~W}$ heat loads across $680 \mathrm{~mm}$ distance at $102.62 \mathrm{~K}$ with $3.1 \mathrm{~K}$ temperature difference [8]. Enhanced thermal performance of the thermosyphon heat pipe and volume fraction of nanoparticles have a great effect on the reduction of the temperature, the evaporator section and increase the heat transfer coefficients can be achieved by utilization of the water based iron oxide nanofluids as the working fluid [9]. Under the same operating conditions the heat transport capacity of sintered wick heat pipe is $14.3 \%$ more compared to mesh wick heat pipe has been found [10]. Heat pipes are now used in power industry because of their low polluting emissions \& creating more efficient system [7].

Rigorous understanding of the wick material parameters is required to study the influence of these parameters on the conductivity. 
Design of experiments was done using taguchi method, which is a statistical method. The influence of factors like heat input, mass flow rate and inclination angle on thermal performance parameters was obtained as the result of data analysis. [11],[12].

\section{EXPERIMENTATION}

\subsection{Experimental Setup}

A total of Nine experiments are conducted using a Copper heat pipe with meshed wick shown in figure 1 with specification shown in table 1, and experimental setup shown in figure 2. By varying orientations, variation of heat input and mass flow rates experiments are conducted shown in Table 2.

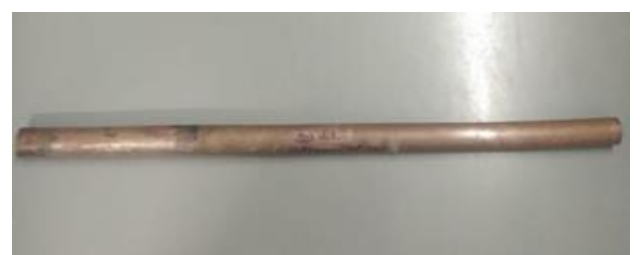

Fig 1. Copper heat pipe with meshed wick

Table 1. Specifications of het pipe

\begin{tabular}{|l|l|}
\hline Paramters & \multicolumn{1}{c|}{ details } \\
\hline Heat pipe length: & $565 \mathrm{~mm}$ \\
\hline Evaporator chamber length: & $200 \mathrm{~mm}$ \\
\hline Adiabatic chamber length: & $165 \mathrm{~mm} 20$ \\
\hline Condenser chamber length: & $200 \mathrm{~mm} 20$ \\
\hline Outer Diameter of the heat pipe: & $15.88 \mathrm{~mm}$ \\
\hline Inner Diameter of the heat pipe: & $14 \mathrm{~mm}$ \\
\hline Thickness of the wick: & $0.5 \mathrm{~mm}$ \\
\hline Working Fluid: & Methyl alcohol \\
\hline Fill Ratio: & $50 \%$ \\
\hline
\end{tabular}

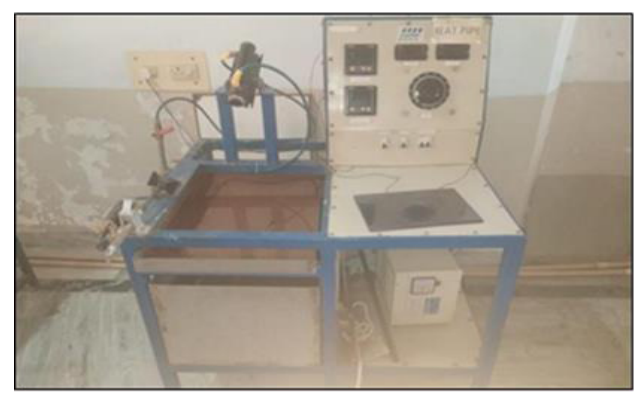

Fig. 2: Experimental Setup

\subsection{Methodology}

Heat pipe is fixed in the experimental setup through the funnel. Then switched on the heater connected at the evaporator end and the water pump. The rate of the water is adjusted as desired using the control valve. The required heat input is given using the control panel knob.
The inclination angle is set using a magnetic dial indicator. The heat input is increased gradually from $25 \mathrm{~W}$ to $150 \mathrm{~W}$ with each increment of $25 \mathrm{~W}$. The inclination angles and the mass flow rate are adjusted as per the optimization table. The same procedure is used throughout all nine experiments.

With the given heat input the variation of the values of the thermal performance parameters is calculated with the variation of the mass flow rate and inclination angle. Following formule wer used to calculated given in equation 1 and 2, Heat input at the evaporator (Qin), Thermal Resistance (R)

Qin $=\mathrm{V}^{*} \mathrm{I}$ Watt

$\mathrm{R}=\mathrm{Te}-\mathrm{Tc} / \mathrm{Qin}$

Where

Water inlet temperature (Tin)

Water outlet temperature (Tout)

Evaporator temperature (Te)

Condenser temperature $(\mathrm{Tc})$

Voltage (V)

Current (I)

3.3 Experimental Design using Taguchi Method: Experiments were designed using taguchi method with 3 levels and 3 factors. The three factors were heat input, inclination angle, Mass flow Rate. The experimental design table is as follows

Table 2. Experimental Design Using Taguchi

\begin{tabular}{|l|l|l|l|l|}
\hline & Factor 1 & Factor 2 & Factor 3 & Response \\
\hline Run & $\begin{array}{l}\text { Heat } \\
\text { Input }\end{array}$ & $\begin{array}{l}\text { Angle } \\
(\text { deg. })\end{array}$ & $\begin{array}{l}\text { Mass } \\
\text { Flow Rate } \\
(\mathrm{Kg} / \mathrm{s})\end{array}$ & $\begin{array}{l}\text { Thermal } \\
\text { Resistance } \\
\left({ }^{\circ} \mathrm{C} / \mathrm{W}\right)\end{array}$ \\
\hline 1 & 75 & 15 & 0.01 & 0.33 \\
\hline 2 & 75 & 30 & 0.02 & 0.37 \\
\hline 3 & 75 & 45 & 0.03 & 0.23 \\
\hline 4 & 125 & 15 & 0.02 & 0.75 \\
\hline 5 & 125 & 30 & 0.03 & 0.44 \\
\hline 6 & 125 & 45 & 0.01 & 0.26 \\
\hline 7 & 150 & 15 & 0.03 & 0.44 \\
\hline 8 & 150 & 30 & 0.01 & 0.37 \\
\hline 9 & 150 & 45 & 0.02 & 0.23 \\
\hline
\end{tabular}

\subsection{ANOVA and Data Analysis}

In ANOVA studied [11] the contribution of each factor on the response parameter and tabulated the $\mathrm{S} / \mathrm{N}$ Ratios. Smaller is better was choosen for the present study is comapred with satyanarayna et al [12].

Table 3: Response Table for Signal to Noise Ratios

\begin{tabular}{|l|l|l|l|}
\hline Level & $\begin{array}{l}\text { Heat } \\
\text { Input }\end{array}$ & $\begin{array}{l}\text { Inclination } \\
\text { Angle }\end{array}$ & $\begin{array}{l}\text { Mass } \\
\text { Flow } \\
\text { Rate }\end{array}$ \\
\hline 1 & 10.344 & 6.420 & 9.989 \\
\hline 2 & 7.110 & 8.134 & 7.967 \\
\hline 3 & 9.511 & 12.410 & 9.009 \\
\hline Delta & 3.234 & 5.991 & 2.022 \\
\hline Rank & 2 & 1 & 3 \\
\hline
\end{tabular}




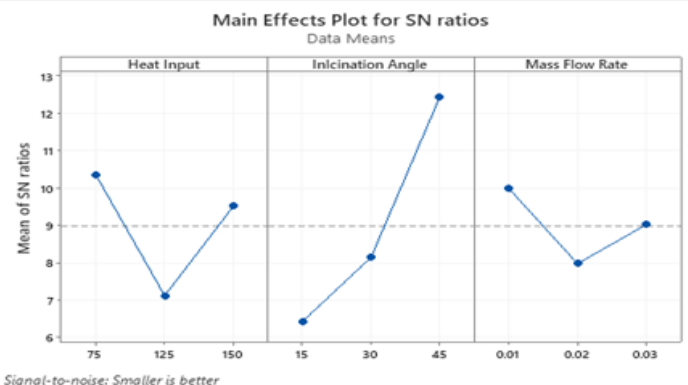

Fig 3. Image of $\mathrm{S} / \mathrm{N}$ Ratio Plot for Thermal Resistance

It can infer from the above figure 3 that the optimum value of the thermal resistance was obtained at the heat input of $75 \mathrm{~W}$, Inclination angle of $45^{\circ}$ and flow rate of $0.01 \mathrm{Kg} / \mathrm{s}$.

\section{Experimental Results and Discussion}

Anova table 4, gives us the contribution of each factor on the Thermal performance parameters. From the table given below it can infer that the inclination angle contributes more to the values of thermal performance parameters as compared with sematic et al [13].

Table 4: ANOVA TABLE

\begin{tabular}{|c|c|c|c|c|c|c|}
\hline Source & DF & Seq SS & $\begin{array}{c}\text { Contributio } \\
\mathrm{n}\end{array}$ & Adj SS & $\begin{array}{c}\mathrm{F}- \\
\text { Value }\end{array}$ & $\begin{array}{c}\text { P- } \\
\text { Value }\end{array}$ \\
\hline $\begin{array}{c}\text { Heat } \\
\text { Input }\end{array}$ & 2 & 32.831 & $10.56 \%$ & 32.831 & 4.61 & 0.17 \\
& & & & & 8 \\
\hline $\begin{array}{c}\text { Inlcinatio } \\
\text { n Angle }\end{array}$ & 2 & $\begin{array}{c}269.02 \\
3\end{array}$ & $86.55 \%$ & 269.02 & 37.7 & 0.02 \\
6 & & 3 & 6 & 6 \\
\hline $\begin{array}{c}\text { Mass } \\
\text { Flow } \\
\text { Rate }\end{array}$ & 2 & 1.844 & $0.59 \%$ & 1.844 & 0.26 & 0.79 \\
\hline Error & 2 & 7.124 & $2.29 \%$ & 7.124 & - & - \\
\hline Total & 8 & 310.82 & $100.00 \%$ & - & - & - \\
\hline
\end{tabular}

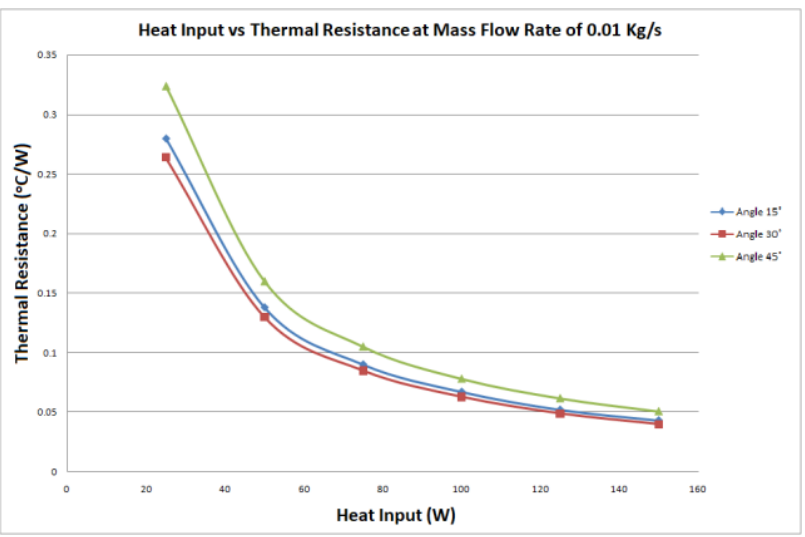

Fig 4. Alteration of Thermal resistance on heat input at different inclination angles and at flow rate of $0.01 \mathrm{~kg} / \mathrm{s}$

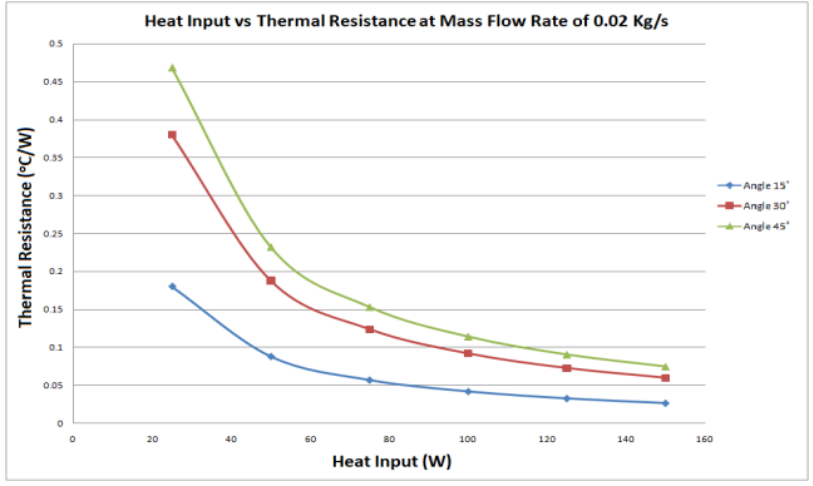

Fig 5. Alteration of Thermal Resistance with Heat input at different inclination angles and at flow rate of 0.02 $\mathrm{kg} / \mathrm{s}$

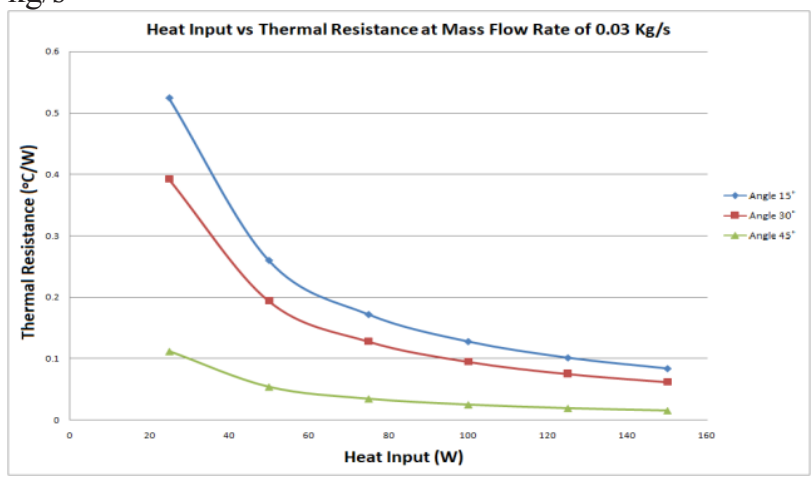

Fig 6. Alteration of Thermal Resistance with heat input at different inclination angles and at flow rate of 0.03 $\mathrm{kg} / \mathrm{s}$

The effective thermal conductivity of a heat pipe depends on the thermal resistance. Thermal resistance can be reduced by providing steep inclination angle as shown in the figures.(4 )and (5). Heat transfer coefficient increased by reducing thermal resistance.

\section{Thermal analysis}

\subsection{Temperature distribution}

Thermal analysis is conducted using ANSYS Fluent to detrmined the influence of the heat load on the heat pipe fluid flow. Variation of parameters like Temperature and Pressure was studied.Mesh is shown figure 7.

Meshing of Heat Pipe:

Mesh number $=60$

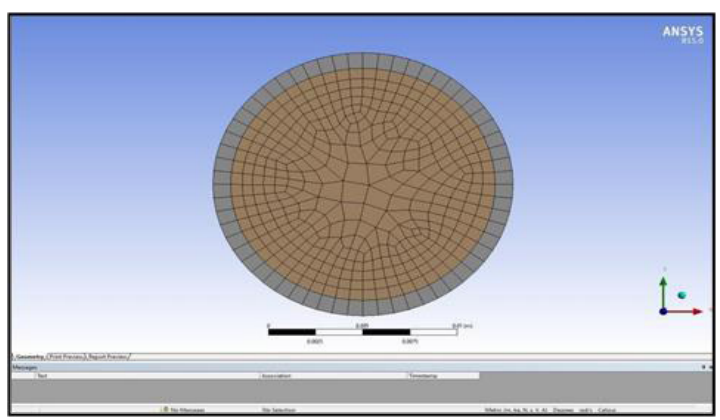

Fig 7. Image of Cross sectional view of Meshed heat pipe 
The heat pipe is first designed using design modeller and then meshing of the heat pipe is done with mesh number 60 .

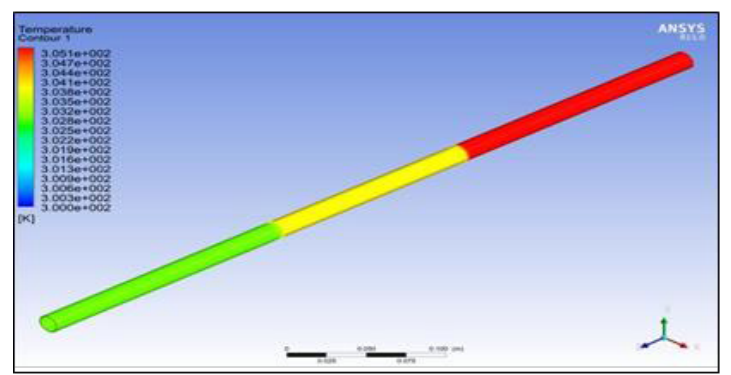

Fig 8. Image of Variation of temperature along axial length of the heat pipe

The above figure 8 shows the variation of the surface temperature along the axial length of the heat pipe.

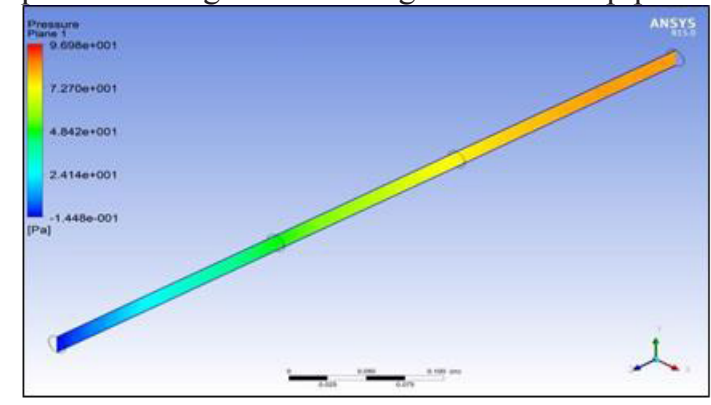

Fig 9. Image of pressure variation along the axial length of the heat pipe

The above figure 9 shows the variation of the pressure due to heat input along the axial length of the heat pipe from evaporator section to the condenser section.

\section{Conclusions}

The outcomes of the paper can be summarized as follows:

i. From the experimental results, the optimum value of thermal resistance at the heat input of $75 \mathrm{~W}$, Inclination angle of $30^{\circ}$ and mass flow rate of $0.02 \mathrm{Kg} / \mathrm{s}$ is 0.124 ${ }^{\circ} \mathrm{C} / \mathrm{W}$.

ii. The optimum values of thermal Resistance at the heat input of $75 \mathrm{~W}$, Inclination angle of $45^{\circ}$ and mass flow rate of $0.01 \mathrm{Kg} / \mathrm{s}$ using ANSYS is is $0.126{ }^{\circ} \mathrm{C} / \mathrm{W}$. The error percentage is varies from $1 \%$ to $2 \%$.

iii. The results also showed that the inclination angle contributes the highest value to the optimum thermal resistance, the mass flow rate shows a minor contribution to the optimum value. As the inclination angle decreases the thermal resistance increases.

\section{References}

1. Singh, Randeep \& Akbarzadeh, Aliakbar \& Mochizuki, Mastaka \& Saito, Yuji \& Nguyen, Thang \& Kao, Bob \& Sataphan, Tanaphan \& Takenaka, Eiji \& Wuttijumnong, V ijit.10.1115/IPACK2005-73278, (2005).
2. Weibel, Justin \& Garimella, Suresh \& North, Mark. International Journal of Heat and Mass Transfer. 53. 4204-4215. 10.1016/j.ijheatmasstransfer.2010.05.043. (2010)

3. Wong, Shwin-Chung \& Lin, Yu-Chung. International Journal of Heat and Mass Transfer. 54. 3921-3926. 10.1016/j.ij heat mass transfer.2011.04.033. (2011)

4. Tummala Suresh Kumar, Kosaraju Satyanarayana, Materials Today: Proceeding, 26 (2), (2020).

5. Jafari D., van Alphen K.J.H., Geurts B.J., Wits W.W., Gonzalez L.C., Vaneker T.H.J., Rahman N.U., Römer G.W., Gibson I. Materials and Design, Volume 191, (2020)

6. Vasiliev, Leonard. (2005). Applied Thermal Engineering.25.119.10.1016/j.applthermaleng.12.0 042003.

7. H. Jouhara, A. Chauhan, T. Nannou, S, Almahmoud, B. Delpech, L.C. Wrobel, Energy, Volume 128,20178.(2017)

8. Hyokjin Cho, Lingxue Jin, Sangkwon Jeong, Cryogenics,Volume 105,2020,102970,ISSN 0011 2275,(2020)

9. Gabriela Huminic, Angel Huminic, Energy Conversion and Management,Volume 76,2013,Pages 393-399,ISSN 0196-8904. (2013)

10. G. Kumaresan, S. Venkatachalapathy, Lazarus Godson Asirvatham, Somchai Wongwises, International Communications in Heat and Mass Transfer,Volume 57,2014,Pages 208-215,ISSN 0735-1933. (2014)

11. Satyanarayana Kosaraju and Chandraker, Satyam. Materials Today: Proceedings 2.4 (2015): 3388 3393, (2015)

12. Satyanarayana, Kosaraju, Anne Venu Gopal, and N. Ravi. International Journal of Precision Technology 5, no. 3-4 (2015): 312-329. (2015)

13. T. Semenic, I. Catton, Int. J. Heat Mass Transfer 52 (21-22) (2009) 5113-5121. (2009) 